\title{
The equative sentence in Finnish Sign Language
}

\author{
Tommi Jantunen \\ University of Jyväskylä
}

\begin{abstract}
It is argued in this paper that equative sentences in Finnish Sign Language (FinSL) conform to the general schema of (NP) NP+(PI+)NP, parenthesis marking optionality of elements. With respect to this schema, it is further argued, (a) that the function of the first NP in equative sentences is always topic; (b) that topics are marked syntactically, prosodically, and morphologically in FinSL; (c) that the preferred organisation of equative sentences in general is topic-comment; (d) that there are two structurally distinct topic-comment structures in FinSL, one having the topic at the beginning of the clause and the other having the topic in the leftdetached clause-external position; (e) that the double-indexing phenomenon (cf. pronoun copy) is functionally a mean to increase textual cohesion; and (f) that the sign PI in equative sentences is a certainty expressing modal device, although it may be in the proces of grammaticalising into a copula.
\end{abstract}

Keywords: Finnish Sign Language, equative sentence, sentence, topic, copula

\section{Introduction}

In this paper I investigate equative sentences (e.g. The capital of France is Paris) in Finnish Sign Language (FinSL). Equative sentences are nominal structures which are used mostly for identificational purposes (e.g. for introduction, naming, and defining), and which have the propositional meaning ' $\mathrm{x}$ is $\mathrm{y}$ ' (Lyons 1977:469-473). In languages such as English and Finnish, equative sentences have been analysed as having the clausal form NP+Copula+NP, the latter NP carrying most of the predicational responsibility (e.g. Lyons 1977:469, Kelomäki 1997:12). However, cross-linguistically, different forms are possible, a non-copular NP+NP, found, for instance, in Russian, being one of the options (cf. Van Valin \& LaPolla 1997:25). 
Traditionally, the equative sentence has been said to have two problems, one relating to its form, the other to its meaning (Kelomäki 1997:12). The former has usually been taken to refer to the grammatical analysis of the constituents of the sentence, i.e. to the question which NP in the sentence has the function of the grammatical subject and which the object (ibid.); this problem can also be taken to be that of identifying the equative sentence's language-specific syntactic form. The second problem, on the other hand, is that of distinguishing equative sentences from semantically inclusive and ascriptive ones (ibid.): given the fact that most formally equative sentences can have an inclusive or ascriptive reading (cf. id., 35), this problem is, to my understanding, often considered to belong more to the realm of philosophy than that of linguistics. ${ }^{1}$

The focus of this paper is, broadly speaking, on the first of the two traditional problems of the equative sentence, the main aim being, specifically, the description and analysis of the syntactic form of equative sentences in FinSL. As far as I am aware, the form of equative sentences per se has not been properly researched in any sign language so far, although Herrero-Blanco and Salazar-García (2005) have discussed some features of equative and other nominal sentences in LSE (Spanish Sign Language), and implicit mentions of the sentence type can be found, for example, in textbooks (e.g. Sutton-Spence \& Woll 1999:54). With regard to FinSL, Rissanen (1998) has also touched upon the issue. In her treatise on nominal and verbal signs and their morphology she states that the equative sentence is one of the basic sentence types in FinSL, and that it consists of nominals and their locations (id., 207); according to Rissanen there is no overt copula in FinSL equative sentences - implying the Russian-like NP+NP form (a similar form is proposed by Herrero-Blanco \& Salazar-García 2005 also for LSE) - but she suggests that the double indexing (cf. pronoun copy) found in both of her two examples may have some predicating copulalike function (Rissanen 1998: 207-209). An example of Rissanen's equative sentence demonstrating double indexing is given in (1) (transcription and translation follow the original, with the exception of the first plus sign that has been corrected here from the original hyphen; for coding and transcription conventions used in this paper, see Appendix 1).

(1) HENKILÖ-3[+]OSOITUS-3 PROFESSORI+HENKILÖ-3 OSOITUS-3 person-3 index-3 professor person-3 index-3 'He is a professor.' (Rissanen 1998:207)

Theoretically, the study presented in this paper is situated in the framework of functionalism. In particular, the study relies on RRG's (Role and Reference Grammar, 
Van Valin \& LaPolla 1997) notion of sentence, and uses Halliday's (1994) SFG (Systemic Functional Grammar) as the main basis for explaining the variation in sentence form; the functions of the units within sentences (e.g. the function of the sentence initial NP) are considered from the point of view of the contributions made to the study of information structure, especially topicality (e.g. Chafe 1976, Halliday 1994). On the methodological side, the study is corpus-based: data is drawn both from the Basic Dictionary of FinSL (Malm, ed. 1998) example sentence corpus (see Suvi) and from the intuitions of native FinSL informants. The core of the data consists of 19 declarative/affirmative equative sentences which have all been thoroughly discussed with native FinSL signers.

This paper is organised as follows: Section 2 explores in more detail the notions of sentence and equative sentence used in the study; Section 3 describes both the data and results of the study; Section 4 presents an analysis of some of the key units within FinSL equative sentences; Section 5 summarises and discusses the findings of the study concerning the general form of the FinSL equative sentence. Section 6 presents conclusions.

\section{On the notions of sentence and equative sentence}

The definitions of a sentence are manifold, varying from the more psychological to the more formal. A prime example of the former is the classical explanation, 'a sentence is the linguistic expression of a complete thought' (cf. Itkonen 1966:299 and other introductory textbooks on linguistics), whereas the widespread modern linguist's definition, 'a sentence is a structural unit consisting of a finite verb and its nominal companions', is an example of a more formal one (cf. Karlsson 1994:109 and almost every other introductory text on linguistics). Needless to say, no definition has yet been proved to be comprehensive: psychological views usually lead to hermeneutic circles (how to define thought, for instance?) whereas more formal definitions are usually too narrow (for example, what to think of nominal equative sentences which have no verb in them?).

Indeed, in the literature there is no consensus as to what a sentence actually is, and because of this the concept is perhaps best seen as a theory-dependent one. In some theories, like Halliday's (1994) SFG, the sentence is considered solely as a unit of written language. However, although the notion of sentence may have its origin in research into written texts (e.g. Brazil 1995:227), most theories still regard the 
sentence as an essential unit for research into non-written, i.e. spoken or signed, language.

One central question relating to the sentence is whether it is a structural unit or not. Again, there have been supporters for both views. For example, de Saussure ([1916]1983) considered the sentence to be a unit of speech, or parole (id., 122); there were no sentences for him in langue, only combinations of syntagmatic units of general type (id., 123). For Bloomfield (1933), on the other hand, the sentence was strictly a unit of structure: according to his classical definition, a sentence is an independent linguistic form, not included by virtue of any grammatical construction in any larger linguistic form (id., 170). Overall, in modern linguistics, the bloomfieldian view of the sentence as a structural unit has now (since Chomsky 1965) become the dominant one, the term utterance being used mostly for units of parole (e.g. Bussmann 1996:427, 509). This is the practice followed also in this paper.

In the study presented in this paper, a sentence was understood in the typologically motivated sense of RRG (cf. Van Valin \& LaPolla 1997:22). This view is summarised in the next section (2.1). The following section (2.2) presents an application of RRG's view of the sentence to equative structures; the schema of equative sentence presented in this section was used in this study both as the maximal structure which an utterance could have in order to count formally as an equative sentence and as the theoretical basis in the syntactic analysis of FinSL equative sentences.

\subsection{Sentence in $R R G$}

RRG (Role and Reference Grammar) is a functional theory of language developed mostly by Robert D. Van Valin. Like most functional theories, RRG agrees that language is a system of communicative social action, and that grammatical structure can only be understood with reference to its semantic and communicative functions (Van Valin \& LaPolla 1997:13). Accordingly, in contrast to generative approaches, RRG posits a direct link between syntax and semantics, and assumes no multiple levels of syntactic representation (id., 21).

In short, a sentence in RRG is a structural unit consisting maximally of the clause and extra-clausal, left- and right-detached positions in which elements such as topics and tags may appear (cf. Van Valin \& LaPolla 1997:38); typically, left- and right-detached positions are separated from the clause by pauses or intonation breaks (id., 36-37). A diagram representing this maximal structure is given in Figure 1. 


\section{\{Figure 1\}}

In RRG, the main unit within the sentence is the clause. The structure of the clause (see Figure 1) is based on two universal contrasts. First is that between predicating and non-predicating elements; every language distinguishes predicating elements from those not predicating (Van Valin \& LaPolla 1997:25). Second is the contrast between arguments of the predicate and non-arguments; every language makes the distinction between units required by the semantics of the predicate and those not required by it (ibid.). The predicate, which may be a verb, an adjective, or a nominal of some sort, defines the nucleus which is the main syntactic constituent in the clause (id., 26). Arguments of the predicate are syntactically core arguments which together with the nucleus constitute the clausal core; non-arguments form the periphery (ibid.).

In some languages it may be useful to assume that the clause includes specific pre- and postcore slots. These slots differ from the left- and right-detached positions in that there are no pauses or intonation breaks in between them and the rest of the clause. Typically the postulation of pre- and postcore slots in languages is motivated by the research into question words; for example, in English WH-words are analyzed to occur in the precore slot whereas in Japanese they are taken to occur in the postcore slot (Van Valin 2005:5-6). For the simple reason that the present equative sentence data from FinSL includes only affirmative/declarative sentences (see Sections 1 and 3 ), the existence of pre- and postcore slots in FinSL is not dealt with in this paper (see, however, Section 4.2).

It should be noted that the sentence in Figure 1 is a simple one. A sentence may also be complex, in which case it contains multiple clauses (Van Valin \& LaPolla 1997:29). In this paper, however, only simple sentences are considered.

\subsection{The maximal structure of the equative sentence in $R R G$}

For the purposes of the present study, introduced in more detail in Section 3, a schema of a logically maximal equative sentence was needed to help to distinguish relevant utterances (i.e. formally equative structures) from those which are not relevant (i.e. not formally equative structures). In the literature, this schema was suggested to be NP+Copula+NP (henceforth: traditional schema; e.g. Lyons 1977:469, Hakulinen \& Karlsson 1979:93, Bussmann 1996:150, Kelomäki 1997:12, Halliday 1994:122). However, when considered from the point of view of RRG, the traditional schema was found insufficient: in RRG, the traditional schema did not cover the whole domain of the maximal sentence, but only that of the (equative) clause (cf. Figure 1 in Section 
2.1). Consequently, in order to do justice to RRG's conception of the sentence, a new schema for the maximal equative sentence conforming to RRG's view was devised. This schema is given below in (2) (L-d-p = left-detached position, Non-pred. = nonpredicating, Pred. = predicating, $\mathrm{R}-\mathrm{d}-\mathrm{p}=$ right-detached position; elements combined by plusses are treated intraclausal):

(2) $\quad \mathrm{NP}_{\mathrm{L}-\mathrm{d}-\mathrm{p}} \mathrm{NP}_{\text {Non-pred. }}+$ Copula or equivalent $+\mathrm{NP}_{\text {Pred. }} \mathrm{NP}_{\mathrm{R}-\mathrm{d}-\mathrm{p}}$

With respect to the traditional schema, there are two major additions in schema (2). The first is the acknowledgement of extra-clausal, left- and right-detached positions. The addition of these two positions to the schema of maximal equative sentence makes it cover more relevant structures than the traditional schema; the elements (possibly) occupying the left- and/or right-detached positions are assumed to be NPs on the grounds that equative sentences are by definition nominal structures. ${ }^{2}$ The second major addition relates to the treatment of the free unit in between the two NPs: although in many cases the unit is best analysed as copular, Pustet's (2003) study on copulas suggests that the copular interpretation may not always be the most appropriate one; the copula-like unit, such as shì in Mandarin Chinese, may also be given the status of, for instance, a pragmatic particle (id., 59-60). A further refinement in schema (2) is also the more straightforward statement that the predicational responsibility is on the second (obligatory) clausal NP.

In this paper, schema (2) is seen first and foremost as a methodological and analytical device; for example, it is not expected that FinSL or any other language should necessarily have equative sentences corresponding to the maximal structure of (2). However, this does not mean that the maximal structure in schema (2) lacks empirical grounding: example (3) from colloquial Finnish displays a simple equative sentence consisting of a clause (se on Honda 'it is Honda') and both left- and rightdetached NPs (cf. Hakulinen \& al. 2004:972, 1013).

(3) Peltola-n auto, se on Honda se se-n merkki.

Fielding-GEN car it be:COP Honda it it-GEN make

'Mr Fielding's car, it is Honda, the make of the car.'

The extent to which FinSL equative sentence in general conforms to schema (2) is discussed in Section 5. 


\section{The research}

In this Section the study on the form of equative sentences in FinSL is presented. Section 3.1 discusses the data and methodology. Section 3.2 describes the results.

\subsection{Data and method}

The main data for the study of FinSL equative sentences comes from The Basic Dictionary of FinSL example sentence corpus (BDFinSL-corpus, see Suvi) which is so far the largest corpus available for FinSL. Altogether the corpus consists of roughly 5 000 video clippings each identifiable as one signed sentence or minitext. The sentences/minitexts were prepared by native deaf FinSL signers with the objective of creating a context as natural as possible for the lexemes presented in the dictionary. By and large, the BDFinSL-corpus is taken to represent the standard everyday variety of FinSL (cf. Malm, ed. 1998:7) although in some respects it is likely to show a slight emphasis on the variety used in southern Finland (ibid.). Another downside of the corpus is its slight idiolecticity, and from the data handling perspective the fact that the videotaped material has not been indexed in any reasonable way (see below).

In addition to the BDFinSL-corpus, data have also been collected rather randomly from native FinSL signers using the traditional methods of elicitation and observation, including unstructured interviews. All informant-related data gathering took place in Jyväskylä University, the informants being either my native signer colleagues or students. In general, the informants' data has been used primarily to support the analysis stage.

The data from the BDFinSL-corpus was extracted in two stages. The first stage consisted of the investigation of Finnish translations of the FinSL sentences/minitexts. These translations were provided in the dictionary and they were made by bilingual (Finnish/FinSL) hearing signers on the basis of the original signing; translations were chosen to be the optimal starting point for the data extraction because the corpus lacked all other relevant search options. During the first stage, all translations that met both the formal and semantic criteria of basic Finnish equative sentence - i.e. those translations that had the clausal form NP+Copula $+\mathrm{NP}$ and that were semantically primarily equational and not, for example, ascriptive (see Hakulinen \& Karlsson 1979:93) - were collected. As a result of this process, 30 Finnish equative sentences were identified (see Appendix 2).

In the second stage, the FinSL utterances that had served as the source material for the 30 Finnish equative sentence translations were subjected to further 
investigation. First, a rough basic glossing of each FinSL utterance was made. Second, each FinSL utterance was scrutinized in terms of its structure and semantics.

Following the principle of including in the data only utterances that (i) conformed to the schema (2) and (ii) were semantically primarily equative, a sample of 19 FinSL sentences was finally settled upon. This sample formed the core data for this study (see Appendix 2, the lines marked with an asterisk).

It was not originally assumed that the translational equivalence between the FinSL utterances and their Finnish translations would be 100 percent accurate. However, it was still rather suprising that only 19 FinSL instances of the total 30 (instances translated into Finnish as equative sentence) fulfilled the above mentioned criteria (i) and (ii). Of the excluded 11 FinSL utterances, 8 were screened out because they were clear instances of (simple or complex) intransitive or transitive structures containing a verbal predicate (KUULUA 'belong to' in Suvi's example 34/2; OLLA/OMISTAA 'to exist/to have' in Suvi's examples 221/4 and 358/1; SYÖDÄ 'to eat' in Suvi's examples 482/3 and 605/4; SUUNTAUTUA 'to direct [one's attention or] oneself' in Suvi's example 962/3; distributionally modified VARASTAA 'to steal' in Suvi's example 1063/3; and ON-AINA 'is always' in Suvi's example 1218/1). Suvi's example $695 / 4$ was a multiclausal construction, and example 746/2 was deemed ungrammatical by the informants because of the presence of the sign OMA 'own' in the second NP. ${ }^{3}$ For Suvi's example $1107 / 5$, video was missing.

The core data was manually further transcribed using the system devised by Paunu (1983) for FinSL. In order to capture the movements and postures of mouth, eyes, brows, head, and torso, the system was slightly extended. Final transcriptions were discussed with native FinSL informants, paying special attention to the wellformedness and internal variational possibilities of each sentence (e.g. what elements could be omitted, and under what conditions). For the general coding and transcription conventions used in this paper, see Appendix 1.

\subsection{The results}

3.2.1 The types of equative sentences in FinSL

From the data, three distinctive forms of equative sentences in FinSL emerged. These forms together with their distribution in the data are summarised in Table 1.

\{Table 1$\}$ 
As a general observation it can be stated that there were no sentences with rightdetached elements in the data. All extra-clausal elements in the data occurred in the left-detached position.

In the remainder of this paper, the forms of the sentences in Table 1 are referred to as (equative sentence) Type 1, Type 2, and Type 3, respectively. These types are briefly discussed, together with fully transcribed examples, in the following sections.

3.2.1.1 Type 1. Equative sentence Type 1 has the $\mathrm{NP}_{\text {Non-pred. }}+\mathrm{NP}_{\text {Pred. }}$ form which is similar to that implied in Rissanen (1998) and Herrero-Blanco \& Salazar-García (2005). A manifestation of this type in the data is given in (4).

(4) eg3

b

OMA-3 SUKU JÄRVI-N-E-N
own-3 family(name) lake $\mathrm{n}$ e $\mathrm{n}$
oma suku järvi ne n

'His/her surname is Järvinen.' (Suvi 972/3) ${ }^{4}$ In the case of (4), I have analysed the combination of the singular possessive pointing sign OMA 'own' and the sign SUKU 'family' to form the first (non-predicating) NP, and the sequence JÄRVI-N-E-N 'Järvinen' to form the second (predicating) NP of the sentence. However, an alternative analysis for the phrase structure might be offered: on the grounds that eye gaze alone can be used to establish a nominal referent in FinSL (Rissanen 1985:37, 103), and that there is a blink in between the constant stage of the eye gaze and the sign OMA 'own' - and since blinks tend to occur at phrase boundaries (see Wilbur 2000:228, Sze 2004) - one could argue that the eye gaze preceding the sentence initial pointing sign OMA 'own' constitutes an independent NP. However, although possible, I do not consider this analysis to be an option in the case of (4): from the evidence of previous research (e.g. Rissanen 1985:103; see Wilbur 2000:234 for ASL) and current data (see Section 3.2.2.2), which both suggest that pointing signs (with the exception of those referring to the first person) tend to occur with a preceding eye gaze to the loci of the pointing, I analyse the gaze in (4) to be, not an independent NP, but an element which is associated to the following manual part.

With regard to the nonmanual structure, it should be noted that, apart from the initial eye gaze and blink, the sentence in (4) is characterised by unusual lack of nonmanual behavior. 
3.2.1.2 Type 2. Equative sentence Type 2 has the form $\mathrm{NP}_{\text {Non-pred. }}+\mathrm{PI}+\mathrm{NP}_{\text {Pred. }}$ This type, characterised by the occurrence of the semantically opaque sign PI (the gloss is based on the mouth gesture associated with the sign) in between the two NPs, was the most frequent sentence type in the data $(n=12)$. Two instances of Type 2 are given in (5) and (6) below.

(5)



'Anis is an aromatic herb.' (Suvi 350/1)

(6)

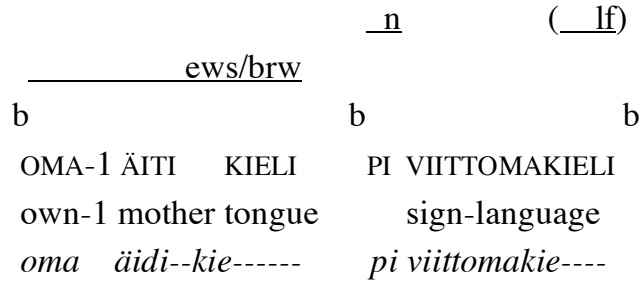

'My mother tongue is sign language.' (Suvi 517/3)

Examples (5) and (6) demonstrate the rather uniform structure of Type 2 sentences, which was found in all of its instances. In (5) and (6), as in the rest of the Type 2 data, both NPs are easily identifiable because of the intervening sign PI, accompanied without exception in the data with the mouth gesture $p i$ and head nod, and the ideal mapping of nonmanual elements (e.g. blinks) with semantic phrase boundaries. The analysis of PI as an independent syntactic unit is based both on the prosody (i.e. on the nonmanual behavior) and on the fact that in the permutation of NPs PI functions as the pivot point with respect to what positions of the NPs are changed (see Section 4.3).

The sign PI and its role in FinSL equative sentences will be further discussed in Section 4.3.

3.2.1.3 Type 3. Type 3 sentences display the form $\mathrm{NP}_{\mathrm{L}-\mathrm{d}-\mathrm{p}} \mathrm{NP}_{\text {Non-pred. }}+\mathrm{PI}+\mathrm{NP}_{\text {Pred. }}$ In practice, this type is an extension of Type 2, having an additional NP in the extraclausal, left-detached position. An example of a Type 3 sentence is given in (7). 
(7)

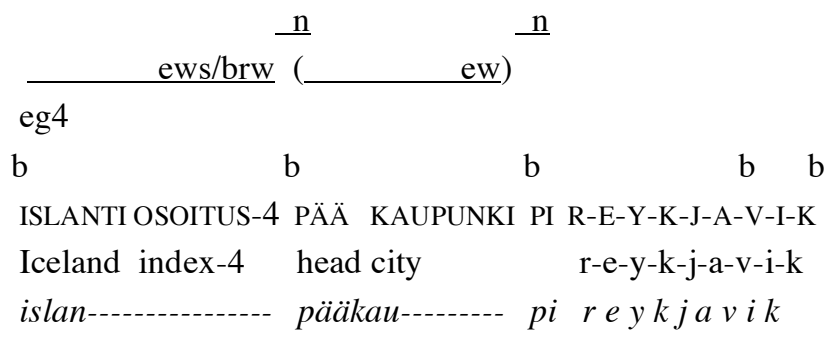

'The capital of Iceland is Reykjavik.' (Suvi 466/3) ${ }^{5}$

In (7), the extra-clausal, left-detached NP is taken to consist of the signs ISLANTI 'Iceland' and OSOITUS-4 'index-4'; the NP is separated from the rest of the sentence by the nonmanual signal "widened/squinted eyes and raised/wrinkled eye brows" and the blink occurring together with a slight head nod. The two clausal NPs, separated by PI, are [PÄÄ KAUPUNKI] and the fingerspelled sequence [R-E-Y-K-J-A-V-I-K]. For comments on the possible nonmanual feature "eyes widened" accompanying the clause initial (non-predicating) NP, see Section 3.2.2.4.

\subsubsection{Nonmanual behavior}

The nonmanual behavior in all of the 19 sentences investigated was substantially uniform. The following sections describe in more detail the main characteristics of the behavior associated with the mouth, eyes, brow, head, and body.

3.2.2.1 Mouthings and mouth gestures. The mouth movements/postures in all of the sentences analysed were almost exclusively Finnish mouthings, that is, silently produced (parts of) Finnish words describing/specifying the meaning of the signs they were associated with (see Rainò 2001 for more discussion). The only clear exception to this rule was the sign PI which was always accompanied with the mouth gesture resembling the production of the sound sequence [pi]. The absence of mouth gestures is at least partially explainable by the fact that mouth gestures tend to occur only with verbal signs (id., 41), and equative sentences consist of nominals alone; consequently, the sign PI is implied to be verbal. ${ }^{6}$

In general, pointing signs in the sentences were not associated with any mouth movement, the only exceptions being the sign OMA 'own' (see Example 6) which was always produced with the mouthing [oma], implying lexicalisation, and the pointing OSOITUS 'index' in sentence 1216/1 (see Suvi) which had the mouthing [tuo] resembling the pronunciation of Finnish demonstrative pronoun tuo. Pointing signs at the beginning of sentences (e.g. OSOITUS 'index', MOLEMMAT 'both of those two'; see 
Examples 10 and 12 in Section 4.2) were produced lips together or slightly opened (the teeth were in this case clenched). Pointing signs (mainly indexes) in other positions in the sentence always occurred with the final part of the mouthing associated with the preceding sign; the mouthing of the preceding sign was stretched over the index. In case of sentence final indexes, this fact was used as a basis to analyse them as a part of the preceding NP, not, for example, as right-detached elements (see Section 4.2).

3.2.2.2 Blinks. Blinks have been argued to occur at sentence boundaries for example in ASL (American Sign Language; e.g. Wilbur 2000:228) and HKSL (Hong Kong Sign Language; Sze 2004). The formal investigation of the sentences in the data showed that blinks occur at sentence boundaries also in FinSL. However, the occurrence of blinks at sentence boundaries was not without exception: only in ten cases out of a total of nineteen did blinks occur just before the beginning of the manual part and right after the end of the manual part of the sentence; in fifteen cases a blink occurred immediately before the beginning of the manual part, and in thirteen cases it occurred immediately after the end of the manual part. Consequently, the marking of sentence boundaries with blinks can only be seen as a tendency.

In addition to sentence boundaries, blinks have been argued to mark also the beginning and end of sentence internal phrases (Wilbur 2000:228, Sze 2004). With regard to the sentences analysed, this seems to be a tendency also in FinSL: for example, the clause initial NP was typically followed by a blink.

It should be noted that blinks did also occur in places other than sentence/phrase boundaries, for instance, in long fingerspelled sequences (see Example 7).

3.2.2.3 Eye gaze. In the data, pointing signs with non-first person referent were always preceded by an eye gaze to the locus of the pointing. ${ }^{7}$ Usually the gaze was only momentary, but with adverbial/demonstrative indexes (e.g. Suvi's sentence 687/1 displayed in the Example 8) the gaze was fixed on the locus for a bit longer. Never, however, did the duration of the gaze exceed the duration of the manual part.

3.2.2.4 Movements and postures of eyes and eye brows. The sentence initial NP was frequently layered with widened/squinted eyes and raised/wrinkled eye brows; ${ }^{8}$ if the NP consisted of more than two signs (e.g. Suvi's sentence 6/1 in the Example 13), the nonmanual marking was slowly neutralised towards the end of the NP. Only in one case (Suvi's sentence 972/3 in the Example 4) was there no perceivable eye/eye browrelated nonmanual marking in the sentence. 
Due to the size and packing of the digital video, separating eye-related behavior from eye brow-related behavior was difficult, and accordingly, the decision was made to treat the two together. Distinguishing the widening of the eyes from squinting, as well as the raising of the eye brows from wrinkling, was also difficult, which was why these phenomena too were treated as one.

With respect to Type 3 sentences, at least in one instance it was possible to say that the clause initial (non-predicating) NP following the left-detached NP occurred with the feature "eyes widened" (see Example 7; cf. the end of Section 4.1 for a brief discussion). However, since this feature was not clearly identifiable in any of the other Type 3 sentences, it is here considered to be an individual case of signer specific behavior.

In general, the eye- and eye brow-related behavior described in this section has been argued to mark sign language topic(s) (e.g. Liddell 1980, Aarons 1996, EbgbergPedersen 2002). In Section 4.1, this argument is pursued for FinSL too.

\subsubsection{Movements and postures of the head. The most common head-related} phenomenon in the data was a nod. All the sixteen instances of the sign PI were accompanied with a nod, always timed perfectly with the manual part of the sign (see Section 4.3). A head-tilt tended to occur also at the end of the sentences, perhaps as an indicator of statement (cf. Liddell 1980 for ASL). During locative pointing indexes, the head was tilted so that the face looked towards the locus pointed at. In general, changes in head postures occurred at NP boundaries suggesting a phrase/sentence boundary marking function (see Sze 2004 for HKSL).

3.2.2.6 Movements and postures of the body. Locative indexes always occurred with body movements or postures conforming to the pointing. Like changes in head movements or postures, changes in body movements or postures also occurred at phrase or sentence boundaries, suggesting a constituent delimiting function (cf. Sze 2004 for HKSL).

\section{Analysis}

In this section, an analysis of the functions of some key units within FinSL equative sentences is presented. In particular, the focus of the analysis is on the functions of the sentence initial NP, double-indexing phenomena, and the sign PI. These three will be discussed in more detail in Sections 4.1, 4.2, and 4.3, respectively. 


\subsection{The sentence initial NP}

In general, the functions of the units within sentences can be considered from three different perspectives: the morpho-syntactic (or formal or grammatical), the semantic, and the pragmatic perspectives. For the purposes of the present analysis the pragmatic perspective was chosen. The main reason for doing so was its recognition of the existence of information structure, which in turn is the structure agreed by most functionalists to exist in some form in every language (see e.g. Van Valin \& LaPolla 1997:201, Kroeger 2004:136). Because the syntax of FinSL has so far not been properly documented, I propose that for the examination of sentence internal constituent functions in FinSL the study of information structure is the most neutral and therefore also the most appropriate choice - from this perspective one can, among other things, completely avoid the use of such traditional labels of grammatical, language-dependent functions as subject and object.

From the point of view of information structure, I argue in this paper that the sentence-initial NP of FinSL equative sentences, which is the unit of interest in this section, has the function of the topic. Topic I understand in the sense presented by Chafe (1976:50), as an element which sets a spatial, temporal, or individual framework within which the main predication (i.e. the comment) is to be interpreted. I take the topic role of the sentence-initial NP to be evident in all the instances in my data, but for a brief demonstration, consider Example (8), which is an instance of a Type 1 equative sentence:

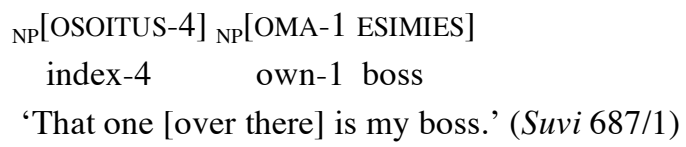

The topic function of the first NP in (8) can be explained by considering the circumstances in which the utterance (may have) occurred. Spatio-temporarily, it is reasonable to assume that there are (at least) three persons involved in the situation: the signer, the addressee, and the one identified as 'boss'; of these the last mentioned is an inactive participant. Individually, it is again reasonable to assume that in the signer's case he/she has the intention of informing the addressee about the identity of the third person, while the addressee, on the other hand, can be assumed not to know the identity of either the signer's boss or the third person. Now, in order to establish an appropriate framework for his/her identifying statement, the signer directs the addressee's attention to the third person by pointing. Consequently, for the addressee, this pointing comes to serve as an 'anchor' (or presupposition) in relation to which 
he/she is to understand the rest of the utterance. Overall, for both the signer and the addressee, the pointing functions to limit the applicability of the following predication to a specific restricted domain (Chafe 1976: 55).

Topics in languages can be marked in different ways, for example by wordorder, morphology, prosody/intonation (Van Valin \& LaPolla 1997:201). With respect to FinSL equative sentences - as well as FinSL in general - I argue further that topics are primarily marked both by the sentence initial position (i.e. syntactically) and by prosodic widening/squinting of the eyes and raising/wrinkling of the eye brows. The sentence initial position is the most common method languages use to mark topics (id., 199); the argument regarding prosodic topic marking, on the other hand, is based on the fact that in the data the first NP of equative sentences occurred frequently with this feature (see Section 3.2.2.4 and Examples 5-7), and that a comparable feature has also been argued to be a topic marker in other sign languages, for example in DSL (Danish Sign Language; Engberg-Pedersen 2002:11).

With respect to nonmanual marking, Example (4) in Section 3.2.1.1 is an oddity. This oddness was reflected to some extent also in the informants' comments about the well-formedness of the sentence, although in general the sentence was considered to be acceptable. However, in the end, it might be that the sentence in (4) does not contain a properly marked topic at all (cf. Example 18 in Section 5).

In previous work on FinSL, Rissanen (1998:117-121) has proposed that nominal pointing signs, e.g. indexes, are used as topic-markers. Although Rissanen does not specify what she means by topic, her observation in general conforms to the findings of this study, and in this paper nominal pointing signs occupying the end of the sentence initial NP are considered to have a topic marking function; this is perhaps enabled by their definiteness (cf. Chafe 1976). An example of Type 3 equative sentence from the data demonstrating topic marking with a semi-functional nominal pointing sign HENKILÖ 'person' is given in (9). ${ }^{9}$

$$
\begin{array}{ccc}
{ }_{\mathrm{NP}}[\text { JEESUS HENKILÖ- } 4] & { }_{\mathrm{NP}}[\mathrm{OMA}-4 \text { IS } \\
\text { Jesus }]+\mathrm{PI}+{ }_{\mathrm{NP}}[\mathrm{JUMALA}] \\
\text { person-4 } & \text { own-4 father } & \text { god }
\end{array}
$$

'Jesus is the son of God.' (Suvi 1138/1)

Two further arguments can be put forward with regard to the information structural analysis of FinSL equative sentences. The first concerns their general organisation: from the data it appears that in general the preferred organisation of FinSL equative sentences is topic-comment. This is an important observation since it implies that this organisation is probably of importance also in other areas of FinSL syntax and it should therefore be observed in the future studies. The second argument relates to the 
typology of FinSL topics: in the present framework, it appears that there are two structurally distinct topic-comment constructions in FinSL, one in which the topic is the clause initial NP (cf. equative sentence Types 1 and 2) and the other in which the topic is the extra-clausal, left-detached NP (cf. equative sentence Type 3). Similar observations have been made, for example, with respect to DSL (Engberg-Pedersen 2002:11) which, in turn, suggests that the typology of FinSL topics may have some cross-linguistic, at least signed language specific validity, too.

A final note should be made that, in addition to the topic function of the sentence initial NP, the clause-initial (non-predicating) NP in Type 3 sentences might also be considered to have a topic function. According to this analysis, the first topic NP is a unit that sets a wider general framework which the second topic NP then narrows down. However, since, for example, the possible marking of these possible second topics is still an open question (see Section 3.2.2.4), the proper treatment of the issue is left to future study.

\subsection{Double-indexing}

In this section, I discuss and analyse the double-indexing phenomenon identified in FinSL (equative) sentences. By double-indexing I mean instances where the location established with a pointing sign (typically index) in the sentence-initial NP is referred back to at the end of the sentence by a second pointing sign (typically index) directed to the same location as the first pointing. This double-indexing is demonstrated in Example (1) in Section 1, as well as in (10) below from the data, and also in subsequent examples in this Section; in (10), the first pointing sign MOLEMMAT 'both of those two' is a dual pronominal index.
(10) MOLEMMAT-3 PI OMA-1 LAPSET OSOITUS-3
both-of-those-two-3 own-1 children index-3
'Those two are my children.' (Suvi 58/2)

The double-indexing phenomenon has been documented in many sign languages, including ASL (e.g. Neidle \& al. 2000), BSL (British Sign Language; Sutton-Spence \& Woll 1999), DSL (Engberg-Pedersen 2006), JSL (Japanese Sign Language; Torigoe 1994), VGT (Flemish Sign Language; Vermeerbergen \& De Vriendt 1994), and LSB (Brasilian Sign Language; Nunes \& Müller de Quadros 2004). Typically, the phenomenon has been labelled "pronoun copy" (e.g. Sutton-Spence \& Woll 1999:54), and indeed, in most studies the phenomenon has been treated only in terms of 
pronouns. However, at least in FinSL, the double-indexing is not limited to pronouns: example (11) from Rissanen (1998) demonstrates a FinSL transitive construction in which the location established by the first topic-marking index is referred back to by the end location of the sentence final verbal sign NÄHDÄ 'to see'; the second index is analysable as being fused into the verbal (transcription and translation of the example follow the original).

\section{(11) LINTU+OSOITUS-4y MIES NÄHDÄ-1-4y \\ bird index-4y man see-1-4y \\ 'The man sees a bird.' (Rissanen 1998:210)}

With regard to FinSL equative sentences, Rissanen (1998:207-209) has suggested that double-indexing may have some predicating function and that the construction (i.e. both indexes together) should be treated as a copula-like element (see also EngbergPedersen 1993:123). ${ }^{10}$ For this copular interpretation of double-indexing, Rissanen offers two arguments: (i) since the second index is aimed at the same location as the first one, it connects the predicating NP to the non-predicating NP in a functionally similar way to the way the copula be, for example, connects the two NPs in English equative sentences; and (ii), it is not unusual for deaf pupils to translate, for example, intransitive FinSL constructions with double indexing into Finnish with intrusive copula on 'be' (e.g. *Tyttö on itkee 'the girl is cries' instead of Tyttö itkee 'the girl is crying'; Rissanen 1998:209; see also Pimiä[Rainò] 1987:70).

I agree in spirit with Rissanen's suggestion that double-indexing may have some predicating function in FinSL. However, regarding the copular interpretation, I find the analysis implausible, and, accordingly, I reject it. My specific reasons for doing so are fourfold. First, concerning Rissanen's argument (i) above, the fact that the doubleindex functions to connect the beginning and the end of the sentence in a functionally similar way to spoken language copulas does not necessarily mean that the doubleindex construction is a copula; for example, the construction can be assigned a more textual/cohesive role (see below). Second, concerning argument (ii), the Finnish word on that Rissanen interprets as an intrusive copula in deaf pupils' translations may just as well be analysed as the homophonous existential verb 'exist'. Third, there are absolutely no modal or temporal grammatical elements (e.g. markers of mood or aspect) in FinSL that could be analysed as being directly associated to the doubleindex; yet all the traditional definitions of copula state clearly that one of the primary functions of copulas is to be a "hitching post" for precisely those kinds of elements (Pustet 2003:3; see also Section 4.3). ${ }^{11}$ Fourth, the double-index is not a stable construction, which implies that it has a more pragmatical function than that 
traditionally assigned to copulas. For example, in cases where there is a first index already present in the sentence-initial NP, but no sentence-final index, it is still possible to produce the sentence with a sentence-final index, as in Example (12) demonstrating a variant of Suvi's Sentence 687/1 (see Example 8 in Section 4.1); conversely, it is possible to drop the second index from all sentences in which it is present. Interestingly, in cases where there is no index in the sentence-initial NP, the production of a sentence-final index alone is ungrammatical, unless the referent is clearly present.

\section{(12) OSOITUS-4 OMA-1 ESIMIES OSOITUS-4 index-4 own-1 boss index-4 'That one [over there] is my boss.'}

As for my own analysis of the phenomenon, I propose that the double indexing is simply an optional pragmatic means which signers use to increase textual cohesion within a sentence (cohesion understood in the sense of Halliday 1994). More specifically, at least in FinSL equative sentences, I treat double indexing as a means to strenghten the interconnectedness of topic and comment, that is, as a way to indicate that the comment is tied to the framework set by the preceding topic. This specific analysis is based on the distribution of the two indexes: in FinSL equative sentences, the first index always occupies the topic NP whereas the second index is always located at the end of the comment NP. ${ }^{12}$ Consequently, it is implied that the latter index signals the end of the sentence as well (see Ros \& al. 2006).

A final note is in order, this time with respect to the constituent status of sentence final index. In this paper I have assumed, from the evidence of spreading Finnish mouthing (see Section 3.2.2.1), that sentence final index is an internal element of the sentence final NP. However, in the future it may be more appropriate to treat the final index as an element occurring in the postcore slot (cf. Section 2.1), and in general, I must also aknowledge the fact that there may be cases (e.g. when occurring without the first index, see above) where this index is best analysed as occupying the rightdetached position. Obviously, the constituent status of sentence final indexes in FinSL needs further investigation.

\subsection{The sign PI}

This section deals with the status the sign PI (glossed in this paper according to its mouth gesture) has in FinSL equative sentences. I begin by presenting a brief 
description of the sign, together with some preliminary conclusions. I then proceed to reject some possible interpretations of PI before finally offering my own analysis of it.

Formally, the sign PI resembles both the signs AITO 'real' and KYLLÄ 'yes' described in Articles 753 and 792, respectively, in the Basic Dictionary of FinSL (Malm, ed. 1998; see also Suvi) (see Figure 2). However, semantically, as indicated by my informants, the sign does not directly agree with the dictionary's characterisations, although all three signs are in a polysemic relation. In fact, the meaning of the sign PI was considered to be extremely difficult to explain which in turn suggests that the sign has only little, if any, lexical content, and that it is, consequently, best seen as a functional unit. Some meanings given by my informants for the sign PI in the equative sentences of the data were: 'that is', 'that precisely', 'expressly', and the characterisation that PI 'strengthens the co-referentiality of NPs'.

\section{\{Figure 2\}}

With regard to the use of PI, all my informants agreed that PI is not an obligatory but an optional element. With a proper modification of nonmanual behavior, PI could have been dropped from all of the sentences in which it occurred in the data without any fundamental change in the propositional meaning of the sentence; conversely, PI could have been added to the sentences which lacked it. This suggests that PI is at least to some extent a pragmatic unit and that it serves perhaps some halliday an interpersonal function. The optionality of PI in equative sentences is an important observation when considering the general form of the FinSL equative sentence. This is an issue considered in more detail in Section 5.

Syntactically, PI is best described as an independent unit, that is, it is not an internal part of either the preceding or the following NP. Evidence for this comes from the fact that in the permutation of NPs demonstrated in (13) below, PI serves as the pivotal point in relation to which the positions of NPs are changed. Prosodic evidence supports this analysis, too: eye and eyebrow behaviour as well as head movements indicate clearly that PI does not belong to either one of the two NPs.

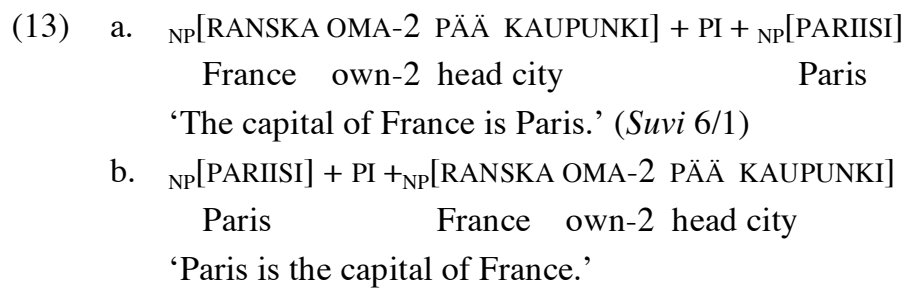


As for the possible interpretations of PI, Rainò (2004), when presenting an example identifiable as a Type 2 equative sentence in her dissertation, analyses the sign as a topic marker (id., 58). However, on the basis of my own data, I do not consider Rainò's view to be a valid one, for the following two reasons: (i) as indicated both by syntactic and prosodic (i.e. nonmanual) behavior, in terms of constituents the sign PI does not belong to the topic-NP (in Type 2 sentences) and it is therefore an unlikely candidate for a topic marker; and (ii) in Type 3 sentences, the sign PI cannot follow and therefore cannot mark either the extra-clausal, left-detached topic-NP.

Interestingly, the sign PI seems to share many of the prototypical characteristics of traditional copulas in spoken languages: it has almost no lexical content, it is both the connector of the clausal NPs (it cannot occur in any other position in equative sentences) and the pivot point in the permutation of these NPs, and also, as implied by the presence of the mouth gesture, it is perhaps more verbal than nominal (Rainò 2001:41; see also section 3.2.2.1), although copulas in general need not be verbs (see Pustet 2003). Indeed, in view of these characteristics, it would be tempting to analyse PI as a copula. However, the copular interpretation of PI is not pursued in this paper. The first reason for this is the fact that, as was the case also with the double-index (see Section 4.2), there are currently no grammatical markers in FinSL that PI can be said to carry; this means that one of the key characteristics of traditional spoken language copulas is not fullfilled by PI. Secondly, the almost idiolectal optionality of PI suggests, again, a more pragmatic function than that of traditional copulas. ${ }^{13}$

As my own analysis of PI I propose, on the grounds of both the polysemic relation PI has to the signs AITO 'real' and KYLLÄ 'yes' (see Figure 2) and my informant's data (i.e. the semantic characterisation and the optionality of PI), that it is, in general, a pragmatic unit which in equative sentences functions to increase the validity of the proposition expressed by the sentence (cf., for example, the pragmatic particle shì which expresses affirmation in Mandarin; Pustet 2003:60). In other words, I interpret PI as a unit that signers use - perhaps rather arbitrarily, but always in the same structural position - in equative sentences to underline the fact that the referent of the non-predicating NP (e.g. 'the capital of France') and the predicating NP (e.g. 'Paris') really is one and the same entity. More technically, I give PI the status of expressing modality, and more specifically, that of expressing certainty (cf. Halliday 1994:75); this analysis rests additionally on PI's marginal verbal status (cf. the mouth gesture $p i$ and the fact that mouth gestures are used typically only with verbals in FinSL).

The distribution of PI in domains other than that of equative sentences is not yet fully known. However, preliminary observations suggest that the modality (certainty) expressing role of PI is not limited only to equative sentences. Example (14) from the 
informant's data demonstrates a semantically ascriptive FinSL sentence in which PI is used exactly as in equative sentences; in (14), PI is best analysed as underlining the signer's personal certainty about the beauty of the woman.

(14) NAINEN PI KAUNIS

woman beautifull

'The woman is beautifull.'

The use of PI in verbal structures - although not properly researched - is extremely rare. Furthermore, in cases where PI seems to be present in verbal structures it is perhaps best analysed as its polysemic partner KYLLÄ 'yes' (see Figure 2) with all its semantics, not as the proper PI. However, it should be noted that even in these cases the sign adds positively to the propositional validity of the structure it appears with.

No treatment of PI is sufficient unless the head nod associated with it is discussed (see Section 3.2.2.5). Syntactically, head nods have been argued to mark emphasis, assertion, existence, and focus; for ASL they have also been argued to be edge markers for signs, phrases, and sentences (Wilbur 2000:229). With respect to the head nod accompanying PI, if it has a syntactic function, all these syntactic analyses must be regarded as possible ones; the function of the nod cannot be unambiguously determined, at least not on the grounds of the present data. However, head nods can also be analysed in terms of phonology and phonetics. From this perspective, a nod may be either a phonological part of the sign or a natural phonetic process resulting from a general tendency of head and body to imitate the path movements of the hands (cf. Woll 2001). In the case of PI's head nod, I propose that the latter phonetic analysis should be accepted. The main argument for this decision contains two parts. First, the head nod occurs with PI also when the sign is produced in isolation (this is also the case with the sign KYLLÄ 'yes', see Figure 2 and the video in Suvi's article 792), and second, it is possible, albeit difficult, to produce PI without the nod. Further support for the decision comes from the fact that there was no comparable nod present in any of the Type 1 sentences (although there tended to be a slight change in head posture in between the two clausal NPs, suggesting a phrase-delimiting function).

Although PI is here given the status of being a pragmatically conditioned certainty expressing modal element, it is possible and perhaps even likely that the sign is in the middle of the process of grammaticalising into a copula. Such grammaticalisation processes from pragmatic units to copulas are far from uncommon (see Pustet 2003:45, 59-61). In the future, the research and documentation of this process is important, as is also observing the role and functions of the head nod. If the head nod can be shown to be an independent unit with a specific, e.g. modality 
(certainty) expressing, function then the sign PI could be argued to be a copula on the basis that it has one of the traditional grammatical functions of the copula, i.e. that of carrying modal markers. So far, the evidence does not support this analysis; the primary function of expressing modality (certainty) rests on the sign PI.

\section{General discussion: representing the form of the FinSL equative sentence}

This section discusses briefly the methodological issue of representing the general form of the FinSL equative sentence. The discussion is assumed to be important for the future study of basic sentence types in FinSL, the term basic sentence type being understood mostly in the sense of Kelomäki (1997) as an emergent sentence schema known intuitively by native language users (id., 125). In fact, the proposal that the equative sentence is one of the basic sentence types in FinSL (cf. Rissanen 1998:207) can even be seen as a primary catalyst for the current treatment of the issue, although the discussion here is limited to its descriptive-representational aspects.

In the study presented in Section 3, three different types of equative structures corresponding to RRG's conception of the sentence were identified. The phrasal schemata of these types are presented in Table 1, but for the sake of the current discussion they are listed also in (15) below.
(15) a. $\mathrm{NP}_{\text {Non-pred. }}+\mathrm{NP}_{\text {Pred. }}$
(Type 1)
b. $\mathrm{NP}_{\text {Non-pred. }}+\mathrm{PI}+\mathrm{NP}_{\text {Pred. }}$.
c. $\quad \mathrm{NP}_{\mathrm{L} \text {-d-p }} \mathrm{NP}_{\text {Non-pred. }}+\mathrm{PI}+\mathrm{NP}_{\text {Pred. }}$
(Type 3)

It was noted in Section 4.3 that the sign PI, present in (15b) and (15c) and analysed as a certainity expressing modal unit, is an optional element. This optionality has an important representational consequence: in proposing a generalisation about the form of the FinSL equative sentence, it is now possible to reduce the number of lines needed from three to two. By Occam's razor, the generalisation expressed in (16) is therefore preferable to that in (15) (parentheses mark, according to the general tradition, optionality of elements).

(16) a. $\mathrm{NP}_{\text {Non-pred. }}+(\mathrm{PI}+) \mathrm{NP}_{\text {Pred }}$

b. $\mathrm{NP}_{\mathrm{L}-\mathrm{d}-\mathrm{p}} \mathrm{NP}_{\text {Non-pred. }}+(\mathrm{PI}+) \mathrm{NP}_{\text {Pred. }}$ 
From (16), an important observation emerges. If PI is optional in (16b) (cf. Type 3 sentences), then one is forced to acknowledge the existence of yet a fourth equative sentence type of FinSL, that is, the type with the structure given in (17).

$$
\mathrm{NP}_{\mathrm{L}-\mathrm{d}-\mathrm{p}} \mathrm{NP}_{\text {Non-pred. }}+\mathrm{NP}_{\text {Pred. }} \quad \text { (Type 4) }
$$

The structure in (17) was not found in the core data, but the informants' data shows that it is indeed a possible manifestation. An example of an equative sentence with this structure is given in (18).

$$
\begin{aligned}
& { }_{\mathrm{NP}}\left[\mathrm{OMA}-1 \text { ISÄ OSOITUS-3] }{ }_{\mathrm{NP}}[\mathrm{OMA}-3 \text { SUKU] }\right. \\
& { }_{\mathrm{NP}}[\mathrm{P}-\mathrm{E}-\mathrm{L}-\mathrm{T}-\mathrm{O}-\mathrm{L}-\mathrm{A}] \\
& \text { own-1 dad index-3 } \\
& \text { own-3 family(name) p-e-1-t-o-l-a }
\end{aligned}
$$

The generalisation expressed in (16) captures the fact that the topic can be, as proposed in Section 4.1, either the function of the clause initial NP or the left-detached NP. Also, if (16a) and (16b) are considered to be structurally distinct topic-comment structures, then the generalisation (16) must be considered as the optimal, descriptionally adequate representation of the form of the FinSL equative sentence too. However, the informants' data suggests that the generalisation can be even further reduced without losing descriptive adequacy. Consider the below example (19) which is an elicited variant of that in (18).

$$
\begin{aligned}
& \text { (19) }{ }_{\mathrm{NP}}[\mathrm{OMA}-3 \text { SUKU }] \quad{ }_{\mathrm{NP}}[\mathrm{P}-\mathrm{E}-\mathrm{L}-\mathrm{T}-\mathrm{O}-\mathrm{L}-\mathrm{A}] \\
& \text { own-3 family(name) p-e-l-t-o-l-a } \\
& \text { 'His/her surname is Peltola.' }
\end{aligned}
$$

Example (19) demonstrates the result of a phenomenon perhaps best characterised as topic deletion (the converse phenomenon, which can also happen, can be characterised as topic addition). In the example, the left-detached NP marked as topic in (18) is deleted, making it possible for the clause-initial NP to take over, because of its becoming sentence initial, the topic expressing function (it is also possible that the clause-initial NP already had this function, see Section 4.1); the topic may be left prosodically unmarked, in which case the example resembles that given in (4) in Section 3.2.1.

The topic deletion illustrated in (19) makes the utterance corresponding to schema (16b) correspond to schema (16a). Representationally, this rank-shift is evidence for the decision to treat the extra-clausal topic NP in (16b) as an optional 
element, which in turn allows one to state the generalisation regarding the form of the FinSL equative sentence in just one line. This line, given in (20) below, is taken in this paper to be the optimal representation of the general form of the FinSL equative sentence.

(20) The general schema of the FinSL equative sentence

$$
\left(\mathrm{NP}_{\mathrm{L}-\mathrm{d}-\mathrm{p}}\right) \mathrm{NP}_{\text {Non-pred. }}+(\mathrm{PI}+) \mathrm{NP}_{\text {Pred. }}
$$

Two short comments regarding the schema in (20) are in order. First, the schema must not be taken as a complete description of the form of the FinSL equative sentence. It focuses almost exclusively on the manual phrasal structure, leaving both the nonmanual structure (see Section 3.2.2) as well as the functional level (see Section 4) unaccounted for; in applying the schema, these structures/levels must be dealt with separately. Secondly, the schema in (20) must not be taken to imply the most prototypical - i.e., in the functional sense, most frequent (Givón 2001:38) manifestation of the FinSL equative sentence, either. In fact, the data suggests that the most frequent manifestation is the type $\mathrm{NP}_{\text {Non-pred. }}+\mathrm{PI}+\mathrm{NP}_{\text {Pred. }}(\mathrm{n}=12)$ and not the $\mathrm{NP}_{\text {Non- }}$ pred. $+\mathrm{NP}_{\text {Pred. }}(\mathrm{n}=3)$, as suggested by the general schema. However, the frequency of the occurrence of PI may have something to do with the fact that the sentences in the data were all isolated ones; the less frequent use of PI in real discourse situations was implied by the informants. Consequently, the need for further, textual research on the FinSL equative sentence is indicated.

\section{Conclusion}

In this paper I have investigated, in the framework of functionalism, the form and variation of identificational nominal structures, i.e. equative sentences, in FinSL. Using RRG's notion of sentence, and relying on the data collected both from the Basic Dictionary of FinSL example sentence corpus (see Suvi) and from native FinSL informants, I have argued that the equative sentence in FinSL conforms to the general schema of $\left(\mathrm{NP}_{\mathrm{L}-\mathrm{d}-\mathrm{p}}\right) \mathrm{NP}_{\text {Non-pred. }}+(\mathrm{PI}+) \mathrm{NP}_{\text {Pred. }}$, having the manifestations described in (21) below: 
(21)
a. $\quad \mathrm{NP}_{\text {Non-pred. }}+\mathrm{NP}_{\text {Pred. }}$
(Type 1)
b. $\mathrm{NP}_{\text {Non-pred. }}+\mathrm{PI}+\mathrm{NP}_{\text {Pred. }}$
(Type 2)
c. $\mathrm{NP}_{\mathrm{L}-\mathrm{d} \text { - }} \mathrm{NP}_{\text {Non-pred. }}+\mathrm{PI}+\mathrm{NP}_{\text {Pred. }}$
(Type 3)
d. $\quad \mathrm{NP}_{\mathrm{L}-\mathrm{d}-\mathrm{p}} \mathrm{NP}_{\text {Non-pred. }}+\mathrm{NP}_{\text {Pred. }}$
(Type 4)

With respect to the structures in (21), I have argued from the point of view of their information structure (a) that the function of the first NP in each construction is topic; (b) that topics in FinSL are marked syntactically (by sentence initiality), prosodically (by widening/squinting the eyes and raising/wrinkling the eye brows), and morphologically (by sentence initial NP final indexes); (c) that the preferred organisation of equative sentences in FinSL in general is topic-comment; (d) that there are two structurally distinct topic-comment structures in FinSL, one having the topic at the beginning of the clause (as in 21a and 21b) and the other having the topic in the left-detached clause-external position (as in 21c and 21d), although through the process of topic deletion the latter type topic structures can become the former type structures; (e) that the double indexing phenomenon (cf. pronoun copy) in equative sentences is a textual means to increase cohesion by connecting the comment to the topic by pointing to the location established by the first index in the topic NP; (f) that the semantically opaque and optional sign PI functions in equative sentences as a certainty increasing modal element, although it may be in the process of grammaticalising into a copula.

The data suggests that further research on constituency in FinSL sentences is needed. The need is also indicated for future research on topic, indexes, the sign PI, and nonmanual elements in FinSL, as well as for textual research on FinSL equative sentence. 


\section{References}

Aarons, D. (1996). “Topic and topicalization in American Sign Language.” In Special issue commemorating the 25th anniversary of the department of general linguistics at the University of Stellenbosch, pp. 65-106. Stellenbosch papers in Linguistics 30. Stellenbosch.

Ahlgren, I., Bergman, B. \& Brennan, M. (eds.) (1994). Perspectives on sign language structure. Papers from the fifth international symposium on sign language research held in Salamanca, Spain, 25-30 May 1992 [Vol. 1]. Durham: ISLA.

Bloomfield. L. (1933). Language. New York: Holt, Rinehart \& Winston.

Boyes Braem, P. \& Sutton-Spence, R. (eds.) (2001). The Hands are the Head of the Mouth: The Mouth as Articulator in Sign Languages. Hamburg: Signum.

Brazil, D. (1995). A Grammar of speech. Oxford: Oxford University Press.

Bussmann, H. (1996). Routledge dictionary of language and linguistics. Translated and edited by G. P. Trauth and K. Kazzazi. London and New York: Routledge.

Chafe, W. L. (1976). "Givenness, contrastiveness, defineteness, subjects, topics, and point of view." In C. N. Li (ed.), Subject and topic, pp. 25-55. New York, San Francisco \& London: Academic Press.

Chomsky, N. (1965). Aspects of the theory of syntax. Cambridge, MA: The M.I.T. Press.

Engberg-Pedersen, E. (1993). Space in Danish Sign Language: the semantics and morphosyntax of the use of space in a visual language. Hamburg: Signum Press.

Engberg-Pedersen, E. (2002). "Grammatical relations in Danish Sign Language: topic and subject.” In A. Pajunen (ed.), Mimesis, sign, and the evolution of language, pp. 5-40. University of Turku, Publications in general linguistics 3. Turku: University of Turku.

Engberg-Pedersen, E. (2006). Intertwined ellipsis - a multiclausal construction in Danish Sign Language? Paper presented at the DGfS [Deutsche Gesellschaft für Sprachwissenschaft] 2006 workshop How to recognize a sentence when you see one: methodological and linguistic issues in the creation of sign language corpora, 23-24 February, Bielefeld, Germany.

Givón, T. (2001). Syntax. Vol. 1. Amsterdam, Philadelphia: John Benjamins Publishing Company.

Hakulinen, A. \& Karlsson, F. (1979). Nykysuomen lauseoppia. Helsinki: SKS.

Hakulinen, A., Vilkuna, M., Korhonen, R., Koivisto, V., Heinonen, T.R. \& Alho, I. (2004). ISO suomen kielioppi. Helsinki: SKS.

Halliday, M. A. K. (1994). An Introduction to Functional Grammar. 2nd Edition. London: Edward Arnold. 
Herrero-Blanco, Á. \& Salazar-García, V. (2005). "Non-verbal predicability and copula supportrule in Spanish Sign Language." In C. de Groot \& K. Hengeveld (eds.), Morphosyntactic Expression in Functional Grammar, pp. 281-315. Berlin \& New York: Mouton de Gruyter.

Itkonen, Erkki (1966). Kieli ja sen tutkimus. Helsinki: WSOY.

Karlsson, F. (1994). Yleinen kielitiede. Helsinki: Yliopistopaino.

Kelomäki, T. (1997). Ekvatiivilause. [Equative clause; published PhD dissertation with English abstract, University of Helsinki] Helsinki: SKS.

Kroeger, P. R. (2004). Analyzing syntax. A lexical-functional approach. Cambridge: Cambridge University Press.

Liddell, S. K. (1980). American Sign Language syntax. The Hague: Mouton.

Lyons, J. (1977). Semantics. Vol. 2. Cambridge, London, New York, Melbourne: Cambridge University Press.

Malm, A. (ed.) (1998). Suomalaisen viittomakielen perussanakirja. [The basic dictionary of Finnish Sign Language] Kuurojen Liitto ry \& Kotimaisten kielten tutkimuskeskus. Helsinki: KL Support Oy.

Neidle, C., Kegl, J., MacLaughlin, D. Bahan, B. \& Lee, R. G. (2000). The Syntax of American Sign Language. Cambridge, MA, London: The MIT Press.

Nunes, J. \& Müller de Quadros, R. (2004). Phonetic realization of multiple copies in American and Brasilian Sign Languages. Paper presented at the TISLR (Theoretical issues in sign language research) 8, September 30 - October 2, Barcelona, Spain.

Paunu, J. (1983). Viito elävästi 2. Helsinki: FAD.

Pimiä[Rainò], P. (1987). "Havaintoja kuurojen koululaisten tuottamista poikkeamista kirjoitetussa suomen kielessä.” In P. Pimiä \& T. Rissanen, Kolme kirjoitusta viittomakielestä, pp. 49-95. Publications of the Department of General Linguistics, University of Helsinki No. 17. Helsinki.

Pustet, R. (2003). Copulas. Universals in the categorization of the lexicon. Oxford: Oxford University Press.

Rainò, P. (2001). ”Mouthings and mouth gestures in Finnish Sign Language.” In P. Boyes Braem \& R. Sutton-Spence (eds.), pp. 41-50.

Rainò, P. (2004). Henkilöviittomien synty ja kehitys suomalaisessa viittomakieliyhteisössä. [The emergence and developement of personal name signs among sign language users in Finland; published PhD dissertation with English abstract, University of Helsinki]. Helsinki: Kuurojen Liitto ry. [html based CD-ROM].

Rissanen, T. (1985). Viittomakielen perusrakenne. Publications of the Department of General Linguistics, University of Helsinki No. 12. Helsinki. 
Rissanen, T. (1998). The Categories of Nominals and Verbals and Their Morphology in Finnish Sign Language. Licentiate thesis in general linguistics, the Department of Finnish and General Linguistics, University of Turku.

Ros, J., Crasborn, O. \& van der Kooij, E. (2006). Pointing signs and palm-up as signals of clause finality. Paper presented at the DGfS [Deutsche Gesellschaft für Sprachwissenschaft] 2006 workshop How to recognize a sentence when you see one: methodological and linguistic issues in the creation of sign language corpora, 23-24 February, Bielefeld, Germany.

de Saussure, F. ([1916]1983). Course in general linguistics. [Edited by C. Bally \& A. Sechehaye with the collaboration of A. Riedlinger.] Translated and annotated by R. Harris. London: Duckworth.

Sutton-Spence, R. \& Woll, B. (1999). The linguistics of British Sign Language: an introduction. Cambridge: Cambridge University Press.

Suvi $=$ Suvi - Suomalaisen viittomakielen verkkosanakirja [The online dictionary of FinSL]. [Helsinki:] Kuurojen Liitto ry, 2003. Online publication: http://suvi.viittomat.net.

Sze, F. (2004). Blinks and intonational phrases in Hong Kong Sign Language. Paper presented at the TISLR (Theoretical issues in sign language research) 8, September 30 - October 2, Barcelona, Spain.

Torigoe, T. (1994). "Resumptive X structures in Japanese Sign Language.” In Ahlgren \& al. (eds.), pp. 187-200.

Van Valin, R. D. (2005). Exploring the syntax-semantics interface. Cambridge: Cambridge University Press.

Van Valin, R. D. \& LaPolla, R. J. (1997). Syntax. Structure, Meaning and Function. Cambridge: Cambridge University Press.

Vermeerbergen, M. \& De Vriendt, S. (1994). "The repetition of signs in Flemish Sign Language." In Ahlgren \& al. (eds.), pp. 201-214.

Wilbur, R. B. (2000). "Phonological and prosodic layering of nonmanuals in American Sign Language.” In K. Emmorey \& H. Lane (eds.), The signs of language revisited. An anthology to honor Ursula Bellugi and Edward Klima, pp. 215-244. Mahwah, NJ, London: Lawrence Erlbaum Associates.

Woll, B. (2001). "The Sign That Dares to Speak its Name: Echo Phonology in British Sign Language (BSL)". In P. Boyes Braem \& R. Sutton-Spence (eds.), pp. 87-98. 


\section{Appendix 1}

\section{Coding and transcription conventions used in this paper}

\section{Manual behavior:}

PERHE Finnish gloss for a manual sign. In the standard case, Finnish glosses are derived from the Finnish equivalents given to signs in the Basic Dictionary of FinSL (Malm, ed. 1998); the gloss is the first Finnish equivalent. Notation in small caps.

family English gloss for a manual sign. English glosses are written in plain text under the line containing the Finnish glosses.

sign-language A hyphen is used when a single sign is glossed with more than one (English) word.

OSOITUS-3 / A gloss followed by a hyphenated number identifies a pointing sign (e.g. an index-3 index or a directional verbal). The number refers to the location in the signing space (see the chart from Rissanen 1985:18 in Figure 3 below) and indicates either the location to which the sign is directed at, or the location in which the sign is produced at. The number 1 refers to the signer. Letters $y$ and $a$ stand for upper and lower level of articulation, respectively.

\{Figure 3 to this space\}

NÄHDÄ-1-4y If the gloss is followed by more than one number, the numbers indicate the spatial path along which the hand(s) move(s).

N-E-N/ Letters separated by hyphens refer to fingerspelled words in which every letter n-e-n is expressed.

In Rissanen's (1998) examples, plusses are used to signal morphological connectedness. 


\section{Nonmanual behavior:}

Movements/postures of the body:

$\begin{array}{ll}\text { bls } & \text { body leaned to side (left and right are not separated) } \\ \text { blf } & \text { body leaned forward } \\ \text { blb } & \text { body leaned back }\end{array}$

Movements/postures of the head:

$\begin{array}{ll}\text { ls } & \text { head leaned to side (left and right are not separated) } \\ \text { If } & \text { head leaned forward } \\ \text { lb } & \text { head leaned back } \\ \text { n } & \text { head nod }\end{array}$

Eye and brow -related phenomena:

ews eyes widened/squinted

brw brows raised/wrinckled

Eye-related behavior:

eg3 eye gaze (the number indicates spatial location; see Figure 3)

b blink

Mouthings and mouth gestures: Finnish mouthings/mouth gestures are written in italics under English glosses.

Symbols relating to the analysis of spoken language material:

GEN Genitive marking morpheme.

COP Copula.

\section{Miscellaneous:}

${ }_{\mathrm{NP}}$ [VIITTOMAKIELI] Square brackets with a preceeding NP subscript mark the string of signs that belong to the same noun phrase.

$\mathrm{NP}_{\text {L-d-p }}$ NP in clause-external, left-detached position.

$\mathrm{NP}_{\text {Non-pred. }}$ Non-predicating, clause-internal NP in equative sentence.

$\mathrm{NP}_{\text {Pred. }}$ Predicating, clause-internal NP in equative sentence.

$+$ In other examples than those from Rissanen (1998), plusses are used to indicate the clause-internal units.

'real' Single quotation marks indicate English translation. 


\section{Appendix 2}

\section{The data}

The table below lists all the 30 written Finnish equative sentence translations collected in the first stage of the data delimiting process from the BDFinSL-corpus. The 19 translations whose FinSL counterparts formed the core data are indicated by asterisk. The original FinSL examples can be searched and viewed from Suvi through the article and sentence number.

\begin{tabular}{|c|c|c|c|}
\hline & $\begin{array}{l}\text { Article } \\
\text { No. }\end{array}$ & $\begin{array}{l}\text { Sentence } \\
\text { No. }\end{array}$ & The original Finnish sentence and its direct English translation \\
\hline * & 6 & 1 & $\begin{array}{l}\text { Ranskan pääkaupunki on Pariisi. } \\
\text { 'The capital of France is Paris.' }\end{array}$ \\
\hline & 34 & 2 & $\begin{array}{l}\text { Tuo on homodisko. } \\
\text { 'That is gay disco.' }\end{array}$ \\
\hline * & 58 & 2 & $\begin{array}{l}\text { Nuo kaksi tuossa ovat lapseni. } \\
\text { 'Those two are my children.' }\end{array}$ \\
\hline * & 58 & 4 & $\begin{array}{l}\text { Hän on perheensä ainokainen. } \\
\text { 'He/she is the only child in his/her family.' }\end{array}$ \\
\hline & 221 & 4 & $\begin{array}{l}\text { Hän on lahjakas taiteilija. } \\
\text { 'He/she is a talented artist.' }\end{array}$ \\
\hline * & 346 & 1 & $\begin{array}{l}\text { Ruskea läiskä poskessa on syntymämerkki. } \\
\text { 'The brown spot in his/her cheek is a birth mark.' }\end{array}$ \\
\hline * & 350 & 1 & $\begin{array}{l}\text { Anis on maustekasvi. } \\
\text { 'Anis is an aromatic herb.' }\end{array}$ \\
\hline & 358 & 1 & $\begin{array}{l}\text { Åvik ja Runola ovat kuurojen vanhainkoteja. } \\
\text { ’Åvik and Runola are retirement homes for the deaf.' }\end{array}$ \\
\hline$*$ & 466 & 3 & $\begin{array}{l}\text { Islannin pääkaupunki on Reykjavik. } \\
\text { 'The capital of Iceland is Reykjavik.' }\end{array}$ \\
\hline$*$ & 473 & 1 & $\begin{array}{l}\text { Tuossa on yksityiskoulu. } \\
\text { 'That is a private school.' }\end{array}$ \\
\hline & 482 & 3 & $\begin{array}{l}\text { Äiti on kasvissyöjä. } \\
\text { 'Mother is a vegetarian.' }\end{array}$ \\
\hline$*$ & 517 & 3 & Äidinkieleni on viittomakieli. \\
\hline
\end{tabular}

'My mother tongue is sign language.' 


\begin{tabular}{|c|c|c|c|}
\hline & 605 & 4 & Mämmi on perinteinen suomalainen pääsiäisruoka. \\
\hline & & & 'Mämmi is a traditional Finnish eastern meal.' \\
\hline \multirow[t]{2}{*}{ * } & 655 & 3 & Hän on filmitähti. \\
\hline & & & 'He/she is a film star.' \\
\hline \multirow[t]{6}{*}{$*$} & 687 & 1 & Tuo tuolla on minun esimieheni. \\
\hline & & & 'That one [over there] is my boss.' \\
\hline & 695 & 4 & Tuо pöllö on hiiripöllö. \\
\hline & & & 'That owl is a mice owl.' \\
\hline & 746 & 2 & Kuurojen Lehti on Kuurojen Liiton oma julkaisu. \\
\hline & & & 'Kuurojen Lehti is a publication of the Finnish Association of the Deaf.' \\
\hline \multirow[t]{2}{*}{$*$} & 777 & 4 & Lapsen lempilelu оп рири. \\
\hline & & & 'Child's favorite toy is the rabbit.' \\
\hline \multirow[t]{2}{*}{$*$} & 807 & 4 & Isäni on insinööri. \\
\hline & & & 'My father is engineer.' \\
\hline \multirow[t]{4}{*}{$*$} & 823 & 4 & Sisareni on ammatiltaan tanssija. \\
\hline & & & 'My sister's profession is dancer.' \\
\hline & 962 & 3 & Tuo on konsulttifirma. \\
\hline & & & 'That is a consul company.' \\
\hline \multirow[t]{2}{*}{$*$} & 966 & 3 & Viittomakieli on kuuron äidinkieli. \\
\hline & & & 'Sign language is deaf's mother tongue.' \\
\hline \multirow[t]{2}{*}{$*$} & 972 & 3 & Hänen sukunimensä on Järvinen. \\
\hline & & & 'He/her surname is Järvinen.' \\
\hline \multirow[t]{6}{*}{$*$} & 1029 & 2 & Susi on petoeläin. \\
\hline & & & 'Wolf is a predator.' \\
\hline & 1063 & 3 & Hän on ammattimainen autovaras. \\
\hline & & & 'He/she is a professional thief.' \\
\hline & 1107 & 5 & Lintu on Pyhän Hengen symboli. Ei videota! \\
\hline & & & 'The bird is the symbol of holy spirit.' No video available! \\
\hline \multirow[t]{2}{*}{$*$} & 1138 & 1 & Jeesus on Jumalan poika. \\
\hline & & & 'Jesus is the son of God.' \\
\hline \multirow[t]{2}{*}{$*$} & 1207 & 1 & Keltainen on lempivärini. \\
\hline & & & 'Yellow is my favorite color.' \\
\hline \multirow[t]{4}{*}{$*$} & 1216 & 1 & Tuo vanha mies on fyysikko. \\
\hline & & & 'That man is a physicist.' \\
\hline & 1218 & 1 & Perjantai on muslimien pyhäpäivä. \\
\hline & & & 'Friday is muslims' holy day.' \\
\hline
\end{tabular}


Reference of the published version: Jantunen, T. (2007). The equative sentence in FinSL. Sign Language \& Linguistics 10:2, 113-143.

\begin{tabular}{lll} 
type & schema & distribution \\
\hline 1 & $\mathrm{NP}_{\text {Non-pred. }}+\mathrm{NP}_{\text {Pred. }}$ & $\mathrm{n}=3$ \\
2 & $\mathrm{NP}_{\text {Non-pred. }}+\mathrm{PI}+\mathrm{NP}_{\text {Pred. }}$ & $\mathrm{n}=12$ \\
3 & $\mathrm{NP}_{\mathrm{L}-\mathrm{d}-\mathrm{p}} \mathrm{NP}_{\text {Non-pred. }}+\mathrm{PI}+\mathrm{NP}_{\text {Pred. }}$ & $\mathrm{n}=4$ \\
\hline
\end{tabular}

Table 1. The phrasal schemata and the distribution of the three equative sentence types in the core data. 
Reference of the published version: Jantunen, T. (2007). The equative sentence in FinSL. Sign Language \& Linguistics 10:2, 113-143.

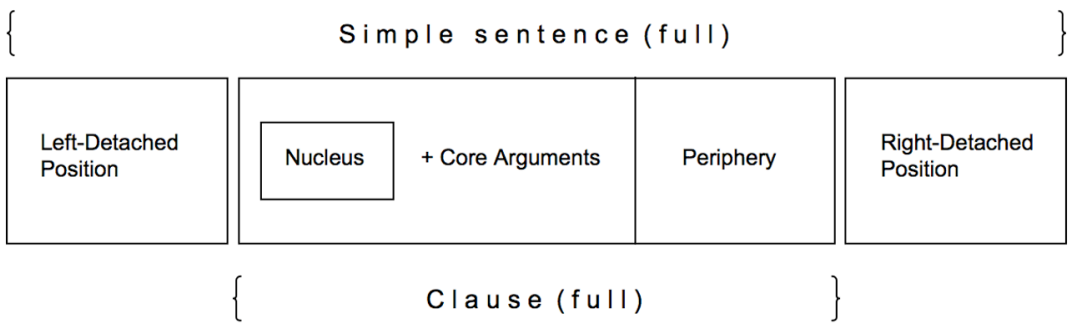

Figure 1. The maximal structure of a simple sentence in RRG. 

Jantunen, T. (2007). The equative sentence in FinSL. Sign Language \& Linguistics 10:2, 113-143.


Figure 2. The FinSL signs AITO 'real' (left) and KYLLÄ 'yes' (right). Photographs are from the Basic Dictionary of FinSL (Malm, ed. 1998), articles 753 and 792, respectively. 


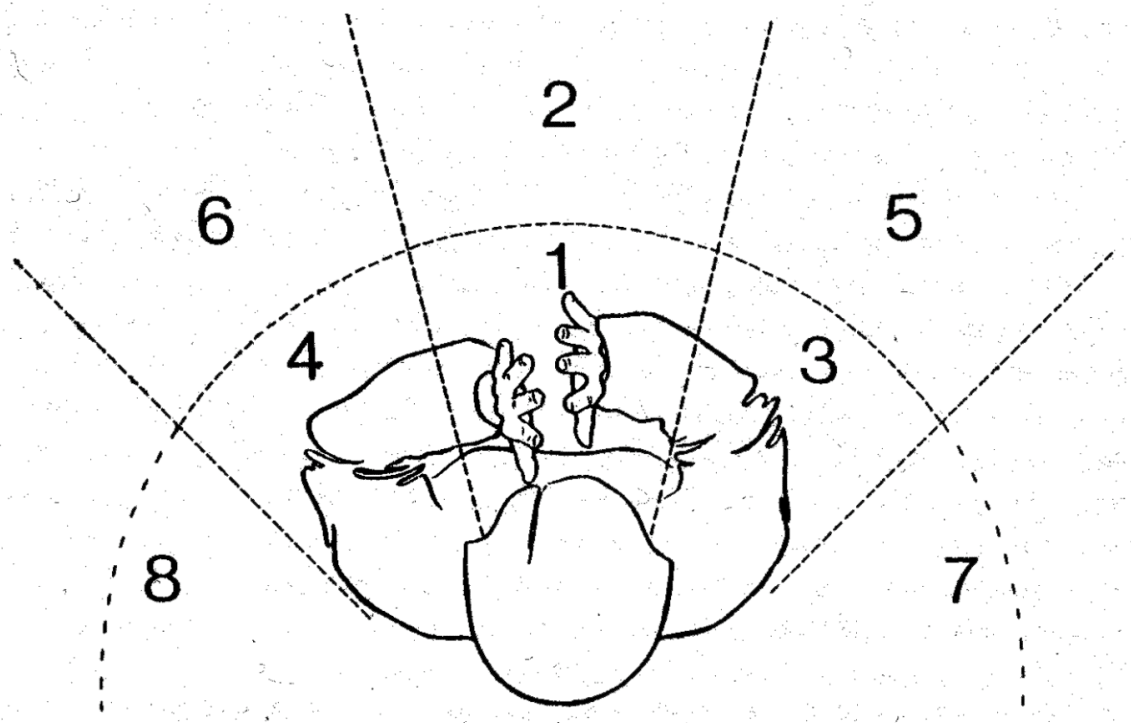

Insert Figure 3 to the location indicated in Appendix 1. 
${ }^{1}$ Examples of formally equative (i.e. NP+Copula+NP) but semantically inclusive and ascriptive sentences in English are Anis is an aromatic herb and The boy is a talented pianist, respectively. Inclusive sentences equate an instance (e.g. anis; hyponym) with a larger class (e.g. aromatic herb; hyperonym). Ascriptive sentences present a characterisation. True ascriptive sentences in English have the clausal form $\mathrm{NP}+$ Copula+AP (e.g. The pianist is very talented).

2 As regards FinSL, the assumption that the elements (possibly) occupying left- and right-detached positions are NPs (and not, e.g., PPs) is further justified by the fact that current research into FinSL acknowledges only two lexico-grammatical categories (cf. 'word-classes'), i.e. nominals and verbals (see Rissanen 1998); the head of any syntactic phrase in FinSL must come from these two categories.

${ }^{3}$ Suvi's multiclausal minitext 695/4 is glossed as follows (slashes indicate clause boundaries): OSOITUS-4 PÖLLÖ OSOITUS-4 / PI OSOITUS-4 / NIMI HIIRI PÖLLÖ / PI OSOITUS-4 (index-4 owl index-4 / pi index-4 / name mouse owl / pi index-4). The clauses can be translated freely as follows: 'There/that is an owl. Right there/that one. It is a mice owl. Right there/that one.'

${ }^{4}$ In all Suvi's examples, English translations follow the Finnish ones.

${ }^{5}$ Traditionally, type 3 sentences have been translated into English as "As for X" structures (e.g. As for Iceland, its capital is Reykjavik). However, in this paper I have not adopted this translation practice because the "As for X" structure in English implies always contrastiveness and the FinSL sentences are not contrastive.

${ }^{6}$ Many FinSL verbals include a mouth gesture as a part of their lexical/phonological structure. Examples of such verbals are LÄHTEÄ 'to go' including a mouth gesture [viu], SAAPUA 'to arrive' including a mouth gesture [ap], and KIUS ATA 'to tease' including a mouth gesture [thh].

${ }^{7}$ In practice, pointing signs referring to location 2 in front of the signer occurred without a preceding, clearly distinguishable eye gaze too, but this is taken to be the result of the fact that the camera which the signers looked at was located on this spot.

${ }^{8}$ A question to be answered in the future is whether the specific facial (eye and eye brow related) actions are characteristic of sentence initial NPs only in equative sentences, or whether they apply to all sentence-initial NPs in FinSL. So far, the syntax of FinSL has not been researched enough to answer this question.

${ }^{9}$ With the term semi-functional sign I refer to a sign which has only some lexical meaning and which is used only in certain restricted domains.

${ }^{10}$ Regarding equative sentences in LSE, Herrero-Blanco and Salazar-García (2005) discuss the existence of the copula too, and posit a sort of covert "zero-copula" (following Hengeveld). I take this to be an odd choice: if one was to suggest that there exists a copula in a language that has normally been analysed as being copulaless, then I think the minimal criterion for the unit in question would be "visibility".

${ }^{11}$ There are no universally valid definitions of copula available. However, a prototypical copula is traditionally said to possess the following features (Pustet 2003): it is semantically empty, it is a linker of 
Jantunen, T. (2007). The equative sentence in FinSL. Sign Language \& Linguistics 10:2, 113-143.

subject and object, it has the function of a syntactic "hitching post" to which verbal inflectional categories like mood and tense can be attached, and accordingly, it is in many cases a verb-like free morpheme "which enables a non-verbal predicate to act as a main predicate under those circumstances in which this non-verbal predicate could not fulfill this function on its own" (id., 4).

12 The topic-comment connector role of double-index is apparent also in the transitive construction in Example (11). However, since not much is known about FinSL verbal sentences at the moment, I do not want to generalize this specific connector role to the domain outside equative sentences.

${ }^{13}$ Traditional spoken language copulas can also be treated as being optional. However, as far as I understand, this optionality of spoken language copulas is not true optionality in the sense that it would depend on "free will", but rather it is paradigmatically conditioned optionality. By this I mean that in spoken languages sentences may be non-copular, for example, in certain tense-aspect classes (e.g. as in present and habitual tense-aspect in Hebrew; see Givón 2001:120), but in other tense-aspect classes (e.g. in Hebrew's past tense) the use of a copula is obligatory (ibid.). This is not the case with the FinSL pi, which is always optional. 